\title{
EHMTI-0064. The prevalence of cluster headache in the elderly is higher in women than in men
}

\author{
C Lisotto ${ }^{*}$, F Mainardi, F Maggioni, G Zanchin \\ From 4th European Headache and Migraine Trust International Congress: EHMTIC 2014 \\ Copenhagen, Denmark. 18-21 September 2014
}

\section{Introduction}

Cluster headache $(\mathrm{CH})$ is considered a disorder of young men, which predominantly begins at age 20 -to- 40 years.

\section{Aims}

We evaluated the gender distribution in patients with $\mathrm{CH}$ aged 65 years and older.

\section{Methods}

For the last 15 years we have observed 261 patients suffering from $\mathrm{CH}$. Out of these cases, 43 patients $(16.5 \%$ of the whole population) were over 65 years.

\section{Results}

In this group of elderly patients, 24 were females and 19 were males. We diagnosed 4 patients with $\mathrm{CH}$ (only one bout, according to the International Classification of Headache Disorder), 25 with episodic $\mathrm{CH}$, and 14 with chronic $\mathrm{CH}$. The onset occurred in ages 35-44 years for $21.4 \%$ of cases, in ages $45-54$ for $16.7 \%$, in ages $55-64$ for $28.6 \%$ and after the age of 65 years for $33.3 \%$. Notably, in the latter subgroup, the females significantly prevailed, accounting for $78.6 \%$ of cases. Out of the patients aged over 65 years the prevalence of chronic $\mathrm{CH}$ was remarkably higher (25.6\%) than in previous ages (9.5\%).

\section{Conclusions}

The increasing number of elderly patients with $\mathrm{CH}$ could be related to an inadequate recognition of this headache disorder, which has been believed for a long time to affect mainly young subjects. Apparently peculiar to female distribution, an increased frequency of $\mathrm{CH}$ appears to occur in middle-age and elderly patients. To our knowledge, we report the patient with the oldest age at onset (a 93-year-

\footnotetext{
Department of Neurosciences, University-Hospital of Padua, Padova, Italy
}

old woman) and the largest case series of $\mathrm{CH}$ elderly patients published in the literature to date.

No conflict of interest.
doi:10.1186/1129-2377-15-S1-C36

Cite this article as: Lisotto et al.: EHMTI-0064. The prevalence of cluster headache in the elderly is higher in women than in men. The Journal of Headache and Pain 2014 15(Suppl 1):C36.
Submit your manuscript to a SpringerOpen ${ }^{\bullet}$ journal and benefit from:

- Convenient online submission

- Rigorous peer review

- Immediate publication on acceptance

Open access: articles freely available online

- High visibility within the field

- Retaining the copyright to your article 